\title{
REVIEWS.
}

\section{THE METHOD OF ACTION OF RADIUM AND X-RAYS ON LIVING TISSUES.}

By Hector A. Colwell. Oxford Medical

Publications. 1935. Price 15/-.

The vast amount of experimental work which has been done in recent years on the action of radiation has brought Experimental Radiology to a stage at which it has important bearings on clinical work, and no therapist can afford to ignore the help and understanding which this science can give him. At the same time, the apparent anomalies in many experiments, the differences between experiments in vitro and in vivo, and the frequent contradictions involved in the contributions of different workers, make it difficult for the therapist to take advantage of the great services such knowledge would render him.

Dr. Colwell has attempted, and with conspicuous success, to give an account of all the important experimental work on this subject. Although this necessarily involves detailed descriptions of technical procedures, the facts are marshalled in a way which makes them easy to understand and no attempt is made to dogmatize when the known facts do not admit of certainty.

After a chapter on the minute structure of the cell, there are sections on the chemical effects of radiation, on the general effects of radiation on cells, and on certain immunity reactions. The last two chapters - which are concerned respectively with resistance to tumour growth and the action of radiation on malignant disease-are of immediate interest to the clinician. The evidence for immunity to cancer, and the part played by the recticulo-endothelial system is described in a clear and unbiassed manner which is typical of the whole book, and the author is to be congratulated on his arrangement of the information available as a result of recent work on radiation on the tumour bed. As a balanced survey of the position reached by the science of Experimental Radiology, and an indication of the lines along which future research may most profitably be pursued, the book should be invaluable to those interested in the subject.

\section{MANUAL OF DIABETES.}

By J. J. Conybeare. Oxford Medical Publications. 1935. Price 6/-.

In this small volume there is given a very good and yet concise account of the diagnosis and treatment of diabetes mellitus. The directions are sufficiently detailed for the appreciation of the various dangers which develop during the course of the disease and to enable the physician to prescribe a varied and palatable dietary. Hence we feel confident that the manual will be a welcome addition to the library of the busy practitioner.

As an appendix there is incorporated the pamphlet "Self-care for the Diabetic" (see below) which is written for the patient himself. We think it a good idea that the pamphlet is available in this way as it shows the doctor what he may with safety and advantage put into the hands of his patient and of which he has at the same time a complete knowledge.

\section{SELF-CARE FOR THE DIABETIC.}

ThIRD EDITION.

By J. J. Conybeare. Oxford Medical Press. 1935. Price 1/-.

This pamphlet is written for the diabetic patient and that it evidently meets a demand is shown by the fact that it has reached a third edition. The general principles of diet and its importance in the treatment of the disease, the methods of testing the urine for sugar and ketones, the use of insulin, the importance of general hygiene and the danger signals of the serious complications are all discussed in language which the patient can understand. In addition, the method of compiling a proper dietary with examples of suitable menus is also given. This pamphlet should be of the greatest help to the patient, or the parent of the patient in the case of the diabetic child, who must be entrusted with so much of the treatment if the best results are to be obtained. 